\section{Lung cancer and chronic bronchitis}

SIR,-Dr D Davies's criticism (11 October, p 100) of the paper by Drs $M$ Caplin and Freda Festenstein (20 September, p 678) is incomplete, for even if the correct comparison, which he describes, between the obstructed and unobstructed bronchitics is made the difference in frequency of lung cancer between them is still significant. What is missing is any statement of the period of survival of the two groups of men. Since $40 \%$ of the obstructed but only $18 \%$ of the unobstructed bronchitics died in the seven years of follow-up, the latter had many more man-years in which to develop lung cancer.

Apart from this, the clinical approach is incapable of providing any reliable data on the presence or absence of a real association between two diseases which have different fatality rates and different likelihoods of in clusion in the clinical series. ${ }^{1}$ The only way of deciding this would be by a prospective study of a sample of the general population to determine the attack rate of lung cancer in men with and without airways obstruction. The fact that Drs Caplin and Festenstein found that $17 \%$ of their lung cancer patients had severe airways obstruction (forced expiratory ratio $<50 \%$ ), while we found only $5 \%$ in cigarette smokers in a sample of working men in West London, appears to conflict with their conclusion that there is a "lack of association" between lung cancer and airways obstruction-but it does not prove the opposite because of the unpredictable effects of selection in any clinical series.

Dr Ian Gregg (11 October, p 100) comments on the apparently small relationship in prevalence surveys between amount smoked and severity of airways obstruction. In our study we found a significant tendency for men with airways obstruction to reduce their cigarette consumption. ${ }^{2}$ In prevalence surveys subjects are usually classified by their current smoking habits so that subjects with low and medium consumption will include many of the former heavier smokers with airways obstruction and the group of current heavier smokers will contain chiefly those who are not susceptible to the development of airways obstruction. This effect will also presumably distort the true relationship between smoking habits and deaths from bronchitis, although these do show a pretty steep gradient in relation to cigarette consumption.

Royal Postgraduate Medical School

Hammersmith Hospital,

1 Mainland, D, American Heart fournal, 1953, 45, 2 Fletcher, C M, Community Health, 1975, 7, 70.

SIR,-If, as reported by Drs $M$ Caplin and Freda Festenstein (20 September, p 678), there is an absence of association between lung cancer and airways obstruction, then Dr I Gregg's interpretation (11 October, $p$ 100 ) can be taken a stage further.

The power of a carcinogen to produce cancer is related to its concentration in or on the susceptible tissue as well as the frequency and length of exposure of the tissue to it. In obstructive airways disease due to chronic bronchitis the underlying factor is hypersecretion of mucus. It seems reasonable to postulate that such mucus would perform its physiological function and trap some, or much, of the carcinogen in the tobacco smoke, so reducing the concentration of the carcinogen that actually reaches the bronchial mucosa. In addition, since mucus is bein constantly secreted, the carcinogen which does reach the mucosa may very well be removed after only a short period of contact. Some of the carcinogen would be trapped in the mucus and expectorated before making contact with the mucosa, so reducing the frequency of the mucosa's exposure to it.

Thus the three factors influencing the effect of a carcinogen-namely, concentration, length of exposure of tissue, and frequency of contact, may all be reduced by the presence and continued secretion of bronchial mucus. If this is so, it would seem that, as suggested by Dr Gregg, those smokers who, owing to host factors, develop obstructive airways disease may be protected against lung cancer whereas those smokers who do not produce hypersecretion of mucus are most at risk.

London NW6

O MORTON

SIR,-Drs Maxwell Caplin and Freda Festenstein (20 September, p 678) found obstructive bronchitis less of ten in patients with lung cancer and simple bronchitis than in those with simple bronchitis alone. This lack of association between lung cancer and severe airways obstruction, they say, requires an explanation.

Any one of the answers suggested by the authors is, of course, possible. On the other hand spurious association due to differences in the way in which the various samples have been selected from the parent population must not be overlooked. In a study described by Berkson ${ }^{1}$ as "a paradigm of what, according to widely held opinion, are the essentials for a perfectly performed experiment of statistical comparison" Pearl ${ }^{2}$ found active tuberculosis in $6.6 \%$ of 816 persons with malignant tumours and in $16.3 \%$ of 816 persons without malignant tumours but of the same race, sex, and age. The conclusion that tuberculosis and cancer are biologically antagonistic "was accepted with utmost seriousness" and a programme of treating cancer patients with tuberculin was instituted. Nevertheless, Pearl's conclusion was not valid. As Berkson ${ }^{13}$ demonstrated with a number of worked examples it foundered because of an important statistical fallacy which ensures that the appearance of association of diseases, either positive or negative, will arise in subpopulations "except in special circumstances" although no association exists in the general population. This he claimed to be true even in prospective studies.

P E BRowN

Department of Community Medicine,

University of Sheffield Medical School,

1 Berkson, J, Proceedings of the Staff Meetings of the Mayo Clinic, 1955, 30. 319. Pearl, R, American fournal of Hygiene, 1929,

9.97 (cited by Berkson).
3 Berkson, J, Biometrics Bulletin, 1946, 2, 47.

\section{Alpha-chain disease cured with antibiotics}

SIR,-Dr O N Manousos and others (25 May, 1974, p 409) reported a case of alphachain disease" with "Mediterranean lym- phoma" which was cured by combined treatment with prednisone, cyclophosphamide, and antibiotics. Laroche $e t a l^{2}$ and Zlotnick and Levy $^{3}$ obtained similar results with or without antibiotics.

In 1970 we reported a complete regression of the clinical, anatomical, and immunological signs of this disease in a patient who received antibiotics only. ${ }^{4}$ Tetracycline and oleandomycin were given by mouth in doses of $2 \mathrm{~g}$ of each daily for 10 months and then $1 \mathrm{~g}$ daily for one year. No drugs have been given since June 1971

Now, six years since the onset, he remains in complete clinical remission (although he developed diabetes mellitus in July 1973) For the past five years the disappearance of the abnormal serum IgA has been verified each year. The last small-intestinal biopsy showed villi of normal architecture and a normal cell population in the lamina propria. The deep lamina propria was only moderately sclerotic. By. immunofluorescence the jejunal mucosa was essentially normal.

It appeared interesting to us to report the long-term evolution of this case since, to the best of our knowledge, this is the only example of alpha-chain disease with

"Mediterranean lymphoma" cured by antibiotic therapy alone and still in complete remission after six years.

J ROGÉ

P DRUET

C MARCHE

F SILVEREANO DE ROISSARD J P CAMILLERI

Hôpital Broussais,

Paris 14

Seligmann, M, et al, Science, 1968, 162. 1396.

Laroche, C, et al, Presse Médicale, 1970, 78, 53. Zlotnick, A, and Levy, M, Archives of Inteinal Medicine, $1971,128,432$

Rogé, J, et al, Pathologie et Biologie, 1970, 18,
851.

\section{Artificial insemination (donor)}

SIR,-It was with great interest that we read your leading article (4 October, p 2) on donor insemination. A service of this type, broadly based within the National Health Service, started in this centre approximately two years ago as a natural extension of a large infertility investigation and treatment clinic. Many of the difficulties outlined in your article have been successfully overcome.

We would entirely agree that secrecy and confidentiality are essential; hence all records of our patients are kept separate from their normal hospital records and are retained within our own unit at all times. In necessary correspondence to all other medical authorities the word "donor" is deliberately deleted, reference being made only to "insemination procedures." This, we believe, helps to protect the patient from casual nonmedical observers who have access to the letters. The procedure itself is carried out in our clinically oriented laboratory unit in a special room set aside for treatment procedures. This is an ideal arrangement, for in a busy gynaecological clinic treatments of this type are impracticable for the reasons outlined in your article.

We have a substantial semen bank available and are often able to inseminate with both fresh and frozen semen from the same donor within the same cycle. We do not agree that donors should always match the husband's physical characteristics in all re- 